\title{
Teología y ciencias sociales: El aporte de Juan Luis Segundo
}

Recibido: 30 de febrero 2019

Revisado: 30 de marzo 2019

Aprobado: 3 de mayo 2019

Alexander Cortés Campos

Costarricense, máster en Antropología por la Universidad de Costa Rica. Licenciado en Teología y en Enseñanza de la Religión por la Universidad Nacional de Costa Rica. Licenciado en Administración Educativa por la Universidad Estatal a Distancia, Costa Rica. Encargado de la Cátedra de Teología y profesor de la Escuela de Ciencias Sociales y

Humanidades de la Universidad Estatal a Distancia, San José, Costa Rica. Correo electrónico: acortesc@uned.ac.cr

Randall Trejos Alvarado Costarricense. Máster en Administración educativa por la Universidad Central, Costa Rica. Licenciado en Teología y en Enseñanza de la religión por la Universidad Nacional de Costa Rica. Encargado de la Carrera de Teología, profesor de la Escuela de Ciencias Sociales y Humanidades e investigador del Programa de Investigación en Fundamentos de la Educación a Distancia en la Universidad Estatal a Distancia, San José, Costa Rica. Correo electrónico: rtrejos@uned.ac.cr

Luis Segreda Mena Costarricense, doctor en Teología por la Universidad Pontificia de Salamanca, España. Egresado del Doctorado en Derechos Humanos por la Universidad Carlos III de Madrid, España. Egresado de la Maestría en Filosofía por la Universidad de Costa Rica y licenciado en Teología y en Estudios Latinoamericanos por la Universidad Nacional de Costa Rica. Labora como profesor de la Escuela de Ciencias Sociales y Humanidades e investigador del Programa de Investigación en Fundamentos de la Educación a Distancia en la Universidad Estatal a Distancia, San José, Costa Rica. Correo electrónico: Isegreda@uned.ac.cr
Resumen: Este artículo pretende abrir diálogos críticos entre la teología y las ciencias sociales, de modo que sus aportes permitan llegar a consensos que beneficien a la sociedad y a los seres humanos. Para ello, a partir del abordaje entre teología y ciencias sociales, se debate acerca del método o métodos que deben promover, se procura explicar la hermenéutica como modelo de interpretación y se cuestionan diversas ideologías que están presentes en la sociedad.

Palabras clave: Teología; ciencias sociales; método; hermenéutica; ideología

\section{Theology and Social Sciences: The Contribution of Juan Luis Segundo}

Abstract: This article pretends to open a critical dialogue between theology and social sciences; so that, it permits to reach consensus that benefits society and mankind. As a result, taking into consideration the approach between theology and social sciences, this document not only debates about the method or methods that must be promoted but also it hopes to explain the hermeneutics as a model for interpretation. Finally, it questions the various ideologies that are current in society.

Key words: Theology; social sciences; method; hermeneutics; ideology 


\section{Introducción}

Antes del desarrollo del método científico, la teología se plantea como meta que la fe se entienda o comprenda desde la razón. En este sentido, Marion (2007) señala que san Anselmo (1033-1109) procura explicar racionalmente la fe cuando expresa fides quaerens intellectum (fe que busca la comprensión), debido a que la fe debe ser comprendida y explicada de forma racional. Asimismo, Ayllón, Izquierdo y Díaz (2018) manifiestan que san Anselmo remarca la importancia de explicar la fe de manera racional, "no en el sentido de razonar para creer, sino de creer para entender mejor: la razón es imprescindible para la comprensión de la fe credo ut intelligam (creo con el fin de entender)" (136). En procura de este propósito es importante buscar un equilibrio entre fe y razón, porque la fe es guía y apoyo de la razón. La fe no puede, por sí misma, encontrar la claridad debido a que esta se logra mediante el uso de la razón.

En esta preocupación de relacionar la fe con la razón, la teología ha encontrado diversos procesos o métodos para lograr este propósito. Aunque se destaca que este concepto de método no es lo mismo antes o después del nacimiento del método científico en el siglo XVIII, debido a que, luego de este siglo, la concepción del método cambia paradigmáticamente.

Antes de esta época y a modo de ejemplo, santo Tomás (1225-1274) define la teología como ciencia de Dios o el estudio de Dios. Se estudia a Dios como objeto de estudio desde Dios mismo. Por consiguiente, el conocimiento de Dios depositado en la sacra doctrina merece entonces el nombre de ciencia; y esta ciencia especial que tiene a Dios como objeto es teología sermo de Deo (palabra de Dios). Ante este planteamiento, ¿quién es entonces su objeto de estudio? Si es Dios mismo, la teología se queda en círculo en sus primeras épocas, pero tiene un giro hacia lo humano con la Reforma protestante y el racionalismo que nace en el Renacimiento y se prolonga con la Modernidad. La preocupación de la teología es entonces lo antropológico: ese análisis del ser humano dentro de sus principales preocupaciones y problemas humanos. El giro de la teología es "ayudar al hombre a la consecución de su fin, que es Dios" (Ladaria 2000, 4).

La teología tiene que ver, por tanto, con Dios que, desde su perspectiva salvífica, le interesa el ser humano, debido a que la teología como producto humano analiza todo desde lo que es Dios mismo sub ratione Dei (bajo el aspecto de Dios). De este modo, Ladaria (2000) describe el tema central de la teología enfatizando en que "Dios es en todo caso el tema de la teología, bien sea porque ésta trata directamente de Dios mismo bien porque se ocupa de las otras cosas en cuanto se ordenan a Dios" (4). Esto significa que se parte de la verdad no evidente para la razón contenida en la revelación, de la cual se extraen racionalmente nuevos conocimientos que se organizan de manera sistemática y son parte del discurso y práctica teológica.

En este sentido, dos autores clásicos buscan otro camino para la teología: Juan Duns Scoto (1266-1308) y San Buenaventura (1221-1274), los cuales 
se fundamentan en la experiencia humana, que no solo es racional, sino emocional (corazón) y que produce un conocimiento enraizado en la cultura como sabiduría. Según esta visión, la teología ya no es fides quarens inteIlectum (fe que busca la comprensión), porque en la teología "por una parte funciona la fe y por otra las ciencias propias de la inteligencia humana" (Espeja 1997, 178).

Juan Duns Scoto y san Buenaventura utilizan el método inductivo, el cual, desde la experiencia mística alimentada por la lectura de las escrituras, permite que se conozcan nuevas verdades relacionadas con la fe. Con este enfoque, se abre la posibilidad de que la teología haga uso de las ciencias del espíritu (bautizadas así por Wilhelm Dilthey [1833-1911]) para conocer la interioridad humana.

En este mismo orden de ideas, santo Tomás utiliza el método deductivo especulativo, el cual permite que se deduzcan nuevas verdades a partir de las grandes verdades de la fe. Por su parte, Karl Rahner (1904-1984) aplica el método antropológico-trascendental como camino para una lectura teológica de la realidad y para la comprensión de la praxis humana. Asimismo, Rahner (2007) explica que, en el siglo XX, la ciencia y la fe tienen encuentros dialógicos, donde la dialéctica se hace inevitable y necesaria para el quehacer de la teología y el nacimiento de una nueva visión, porque la dialéctica permite que se desarrolle un diálogo profundo entre la razón y la fe.

Cuando el teólogo experimenta sus limitaciones, en su quehacer teológico utiliza la razón como capacidad humana para comprender. Sin duda en ello, la filosofía y, por supuesto, las ciencias sociales como disciplinas científicas son de gran ayuda para esta comprensión racional, las cuales utilizan diversos métodos cuyos perfiles procuran aplicar la racionalidad de manera rigurosa. Por consiguiente, este artículo pretende abrir un diálogo crítico entre la teología y las ciencias sociales con la finalidad de llegar a consensos y, así, suministrar aportes a la sociedad y a las personas en particular.

\section{La teología y el surgimiento de las ciencias}

Con la aparición del método de las ciencias naturales, las verdades dejan de ser fundamentadas por la filosofía y todo tiende a basarse en el pensamiento científico, posición que no es muy aceptada en los círculos eclesiales. Desde esta perspectiva, la ciencia es el referente de lo que es verdadero; de ahí, la decadencia de la teología en un contexto donde la rigurosidad de esta disciplina era considerada como ciencia.

Con el surgimiento de las ciencias del espíritu o humanas (hoy ciencias sociales), la teología se inclina por utilizar estas ciencias como instrumentos para cumplir su discernimiento del quehacer de Dios en el mundo, o sea, su enfoque principal deja de estar centrado en Dios mismo para concentrarse en el ser humano (antropocentrismo) que desplaza el teocentrismo medieval y centra la temática teológica en la realidad humana (muy recientemente inclu- 
ye el tema del medio ambiente), dado que la fe se guía por la comprensión que se tenga de la realidad, de allí la necesidad de las ciencias sociales para esclarecer la perspectiva desde donde se practique la fe. Para ello, es necesario recordar que la razón y el entendimiento guían la fe.

Tanto las ciencias humanas como la teología han aspirado a encontrar un método racional desde hace varios siglos atrás hasta la actualidad. El interés de la teología se ha orientado a legitimar sus presupuestos con la ciencia, comprobando la verdad de la fe con la ciencia. A modo de ejemplo, Keller (1957), a mediados del siglo XX, hace el intento de justificar la fe con la ciencia al concordar las verdades de la fe con las verdades de la ciencia por medio de la arqueología bíblica.

Son las ciencias sociales, especialmente aquellas que concuerdan con el carácter emancipador salvífico de lo humano, las que aportan elementos nuevos y significativos a la teología. Así, con el auxilio en las ciencias sociales, la teología se ha visto enriquecida en su esclarecimiento de la realidad que, a su vez, hace más eficaz el quehacer y la práctica teológica.

Efectivamente, esta aspiración de la teología que data del período de la llustración hasta la actualidad es para legitimar sus presupuestos en las ciencias (con ciertas limitaciones en las ciencias naturales o positivas y con más afinidad en las ciencias sociales), dando importancia a sus conclusiones y tomando a estas ciencias como un punto de vista indispensable para el quehacer teológico.

En este sentido, Benzo (1978) manifiesta que el teólogo Karl Barth (18861968) define como su objeto de estudio a Dios en las escrituras, de lo cual deriva toda su teología, dándole a su obra una indudable intención científica que le ha valido la denominación como positivista de la Revelación. "Barth ha comenzado (y ese será siempre su gran mérito), la crítica de la religión, pero seguidamente la ha remplazado por una teología contextual que pone como lugar excelso la Revelación" (83). Asimismo, Velasco (1998) citando a Gibellini, señala que Dietrich Bonhoeffer (1906-1945) fue quien le imputa el positivismo de la Revelación a Karl Barth, después de cuestionar fuertemente su teología.

\section{Las limitaciones del positivismo científico en la comprensión de lo social}

A través de la historia reciente del cristianismo histórico, el positivismo científico, en su relación con la teología, ha tenido diversas controversias: el darwinismo; la bioética, en especial la fertilización in vitro, la reingeniería genética, la clonación y, más recientemente, la robótica. A la vez, ha habido encuentros valiosos y significativos entre teología y ciencia, como el evolucionismo de Teilhard de Chardin (1881-1955); también, se puede mencionar en estos aportes el pensamiento de Paul Ricoeur (1913-2005) (Mancilla, 2006). 
Por otra parte, para Habermas (2005), desde la perspectiva de la emancipación humana, se ha cuestionado el papel de la ciencia y la técnica, las cuales han estado muy marcadas por los intereses de la sociedad de consumo. En efecto, la limitación del positivismo en el campo social ha posibilitado el desarrollo de las ciencias sociales, entre las que la teología se ha visto cada vez más auxiliada. En consecuencia, el enfoque de las ciencias sociales en la dimensión emancipadora ha sido uno de los aspectos de mayor impacto en aquellas teologías que valoran la dimensión salvífica en la historia y que han acudido en su auxilio instrumental.

Habermas (2005) esclarece ese carácter del positivismo científico que tiende a fortalecer una ciencia desligada de la emancipación humana. Carácter que hace sospechoso el papel ideológico de la ciencia y de la técnica que orienta a las personas a buscar otros criterios científicos que no asuman de frente lo humano y lo histórico con un talante liberador. Como es conocido, este autor parte del materialismo dialéctico de la Escuela de Frankfurt que conocemos como teoría crítica. Esta corriente se caracteriza por la relación que establece entre una temática y el análisis estructurald y superestructural de la sociedad. Por lo tanto, la crítica de esta escuela apunta siempre al papel que juega la sociedad de consumo, invisibilizando las posibilidades liberadoras.

Otra limitación del positivismo científico es su rechazo a todo elemento subjetivo, en un mundo donde se esta sumergido de una manera u otra, incluso los científicos positivistas. No es posible evadir o esconder esta dimensión clave del ser humano. Cualquier interpretación, aun las de carácter positivista, está condicionada por la interioridad personal y cultural de cada ser humano, la cual posee un alto grado de subjetividad. La dificultad con el positivismo científico es que este gran porcentaje de subjetividad se ve como un obstáculo y se quisiera eliminar o minimizar la incidencia de este factor subjetivo en las observaciones e interpretaciones de un determinado fenómeno. En la investigación de hechos y fenómenos naturales, en ciencias puras y en el análisis de lo positivo, es posible esta tarea, pero no lo es en hechos y fenómenos sociales, donde lo observado tiene una dimensión de movimiento constante y de complejidad que no es posible aprehenderlo, a menos que se puedan introducir otras categorías que permitan la comprensión del fenómeno.

En esta tarea es imposible aplicar el criterio dualista de lo objetivo-subjetivo a los hechos y fenómenos psicológicos, sociales y culturales, por lo que es necesario aceptar la subjetividad y desde allí interpretar el objeto de estudio que se pretende entender. Este problema de la insuficiencia del método positivista para aprehender los fenómenos culturales, psicológicos o sociales produjo hace varias décadas el desarrollo del método de las ciencias del espíritu, el cual surge precisamente por la insuficiencia del positivismo de responder preguntas que sobrepasan lo empírico y, por ende, son excluidas del método científico lógico matemático (por su carácter sumativo y positivista), porque no se aceptan respuestas insuficientes o incoherentes desde la ciencia pura. Pero, a la vez, las preguntas que surgen del ser humano contemporáneo a la teología son tantas y de tal envergadura que las respuestas desde 
una fe pura serían insuficientes, ingenuas o alienantes. De allí la necesidad que tiene la teología de auxiliarse con estas ciencias en la comprensión del ser humano y de la sociedad.

Algo que ha quedado claro es que el enfoque científico fundamentado en el positivismo, en su relación con la teología, ha provocado controversias irreconciliables: algunos de esos conflictos han sido el rechazo de la Iglesia católica a las ideas de Galileo Galilei (1564-1642) y Nicolás Copérnico (14731543) y las reacciones de las iglesias protestantes de los Estados Unidos a la teoría evolucionista de Charles Darwin (1809-1882). Hoy día se suscitan reacciones en círculos teológicos conservadores relacionados con diversos avances científicos. Aunque tampoco se puede negar que existen encuentros valiosos y significativos de la fe con la ciencia, por ejemplo, el evolucionismo de Teilhard de Chardin. En general, la relación entre fe y ciencia se ha ido truncando por la insuficiencia del enfoque científico positivista aplicado al individuo y la sociedad de plano complejo y en constante cambio, de allí la importancia de las ciencias sociales que contemplan esta particularidad de lo social.

En resumen, al hablar del positivismo, se da por sentado que en el origen de las ciencias sociales se quiso imitar o emular el método de las ciencias naturales que, por esencia, son positivistas. No se explica todo este proceso porque se considera obvio, pero se admite que una aclaración al respecto sería recomendable. Asimismo, no ocurre una evolución en las ciencias naturales, pues la naturaleza de este método en ese campo es esencialmente positivista; más bien habría que hablar más sobre el cuestionamiento a la tendencia positivista dentro de las ciencias sociales, pues se considera que las ciencias sociales, por su complejidad, no deben seguir el método científico de manera mecánica. El objeto de estudio de las ciencias sociales es el análisis del ser humano en sociedad; por ende, se habla de un objeto de estudio en constante movimiento, difícil de aprehender, y es aquí donde radican las diferencias sustanciales que distinguen las ciencias sociales de las ciencias naturales. Esto es su complejidad y su particularidad.

En este contexto de las ciencias sociales, es donde se tienen que ubicar hoy día los diferentes métodos teológicos. Para buscar el ethos teológico, que le dé sentido no solo al discurso teológico, como método, sino cómo este le ayuda a buscar el sentido a la vida de una forma integral con el entorno.

\section{Cambios en el papel de la teología como verificadora de la verdad}

La teología, actualmente, no puede pretender un sitial de honor en el mundo de las disciplinas como lo tuvo en la Edad Media, cuando fue la reina de las ciencias; además, con la filosofía y luego con las leyes fue la ciencia reinante. Con el surgimiento de la modernidad y de las ciencias, las respuestas a las preguntas de la humanidad son imposibles de contestar desde dogmas y tradiciones que responden interrogantes viejas a situaciones antiguas que pocas personas se cuestionan. La teología cristiana viene buscando y a ve- 
ces ha sido arrastrada a encontrar una nueva rearticulación con un mundo cada vez más preocupado por lo humano y para ello ha hecho uso de las ciencias sociales. Ese proceso de búsqueda y de articulación con las ciencias sociales explica todo el desarrollo de las teologías en el siglo XX, como los cambios significativos en la Iglesia católica por medio del Concilio Vaticano II (Floristán y Tamayo 1985).

Por su parte, Pié i Ninot (2005) enfatiza que el teólogo Karl Rahner le da mucha importancia a la revelación porque es salvífica y, por ello, la teología es esencialmente teología de la salvación en la historia y, por ende, en lo humano. Por eso, no se revelan ni se piensan en la teología cosas cualesquiera, sino aquello que hace referencia a la salvación del ser humano. Asimismo, este teólogo tuvo mucha influencia en el Concilio Vaticano II, pues impulsó un giro de la teología hacia lo humano, razón por la cual fue criticado de reducir la teología a antropología.

En este mismo orden de ideas, tanto Gaboriau (1970), en el siglo pasado, como Vigil (2005), más recientemente, externan que este énfasis en lo humano se manifiesta con el surgimiento de diversas teologías contextuales que intentan responder las nuevas preguntas procedentes del mundo contemporáneo: la teología de las realidades terrenas, la teología política europea, la teología negra, las teologías de la liberación en Asia y América Latina, las teologías desde la mujer, entre otras; así como el encuentro con las religiones no cristianas que obligan a la teología cristiana a nuevos enfoques, uno de ellos es la teología de la pluralidad cultural y religiosa.

Estas teologías citadas han tenido incidencia histórica en las instituciones y en la historia reciente en diversas partes del mundo como el Concilio Vaticano II, las Asambleas Generales del Episcopado Latinoamericano, en múltiples iglesias históricas como el Consejo Mundial de Iglesias, la Federación Mundial Luterana, el Consejo Nacional de las Iglesias (EE. UU.), en la relación con otras religiones en el mundo, entre otras. Estas teologías han tenido incidencia en diversos acontecimientos mundiales o regionales, como las reivindicaciones civiles logradas en Estados Unidos en las décadas de los sesenta y setenta del siglo pasado o el final de las dictaduras y de los regímenes represivos de América Latina (Segreda 2011).

No se pueden entender todos los procesos históricos señalados si no se relacionan con el desarrollo de estas ciencias que influyen en la teología y rearticulan una nueva manera de comprender la fe en busca de su eficacia histórica, desfasando métodos teológicos anteriores por métodos que toman en cuenta el desarrollo de estas ciencias y que aportan nuevos criterios de verdad a la teología (Míguez Bonino 1977). Algunos de estos criterios son los siguientes:

- La necesidad de relacionar estas ciencias con la historia.

- El carácter emancipador de las ciencias sociales.

- El rigor que aportan los diversos métodos científicos (planteamiento del problema, delimitación, objeto de estudio, hipótesis de trabajo). 
- El carácter aplicativo o de la praxis, entre otras.

Son tantas las preguntas que surgen del ser humano contemporáneo a la teología que las respuestas desde una fe pura serían insuficientes, ingenuas y hasta alienantes. De allí, la necesidad que tiene la teología de auxiliarse de las ciencias sociales en la comprensión del ser humano, de la sociedad y del entorno.

\section{Relación entre teología y ciencias sociales: la teología de la liberación}

Antes de abordar esta relación entre teología y ciencias sociales es importante aclarar qué se entiende por teología de la liberación y si más bien se debe hablar de teologías de la liberación. Es importante señalar que hay un elemento que unifica las diversas teologías de la liberación: el método; por lo tanto, es válido hablar de teología de la liberación para referirse a todas ellas. En cuanto a la aparición del método científico, no hay duda que se sube a otro escenario y en este se le exige una mayor rigurosidad a la teología. Antes de la aparición de la ciencia en el período del Renacimiento (siglo XV), la teología dependía de la filosofía, como es el caso de la teología de san Agustín en el siglo $\mathrm{V}$ y de la teología de santo Tomás en el siglo XII. Este cambio a partir de la ciencia produce que la teología como ciencia decaiga y que predomine, más bien, el método científico como criterio de verdad y más tarde, en el siglo XIX, con la aparición de las ciencias sociales, la teología adquiere un énfasis socioantropológico que le da nueva vigencia.

Ahora bien, el tema de la ciencia y su delimitación con las ciencias del espíritu es uno de los aspectos más elaborados por Habermas (2005), quien indica la existencia de dos tipos de racionalidad que derivan, a la vez, en dos tipos de ciencia, uniéndose con ello a una larga tradición proveniente de Wilhelm Dilthey y su ciencia del espíritu. Una de estas racionalidades es la sistémica, referida a la racionalidad científico técnica institucionalizada, y la racionalidad del mundo de la vida, relacionada con la opinión y criterios de los sujetos que pertenecen a la sociedad. La ciencia y la técnica corresponden a la primera y se caracteriza por ser una racionalidad con arreglo a fines tendientes a crear condiciones para lograr el control y el dominio de la realidad y que se impone externamente por una racionalidad interesada que les da origen y se presenta neutra y desinteresada, desarrollándose para lograr su reproducción ilimitada. Con ello, en la sociedad moderna, la ciencia y la técnica se convierten en medios de control, tanto de la naturaleza como del dominio político, transformándose en instancias de legitimación.

Ante esta realidad, las ciencias sociales han ido desarrollando su propio método, conocido en sus inicios como método de las ciencias del espíritu, surgido precisamente por la insuficiencia del positivismo a dar respuesta a las necesidades de las personas que viven en sociedad o mundo de la vida. Esta nomenclatura, así como la distinción entre ciencias de la naturaleza y cien- 
cias del espíritu corresponden a dos métodos del conocimiento: la explicación y la comprensión.

Para Habermas (2005), las ciencias naturales son explicativas y expresan en sí mismas una racionalidad interesada que tiende a fines distintos al mundo de la vida. El método de las ciencias del espíritu o ciencias sociales es comprensivo y hermenéutico y propende a una racional comunicativa o intersubjetiva en base a la interpretación del lenguaje. Desde esta perspectiva y dentro del pensamiento teológico latinoamericano, se puede situar a la teología como disciplina y, por supuesto, en diálogo permanente con las ciencias sociales.

Efectivamente, la teología de la liberación tiene como interés primordial la búsqueda liberadora de las mujeres y de los hombres latinoamericanos oprimidos social y políticamente que viven en regímenes represivos, por medio de una praxis liberadora que parte de la fe cristiana (Taborda 1981). Es un paso en la afirmación de la vida como principio axiomático, en favor de los pueblos latinoamericanos originarios que sufren la opresión y la represión de sus gobernantes, así como de sistemas deshumanizantes.

Las preguntas más importantes de las mujeres y de los hombres de fe latinoamericanos son las que provienen de la praxis, esto es, de la vida que busca la liberación de estructuras injustas. Son preguntas de la experiencia humana usualmente evadidas por las instituciones religiosas oficiales, aunque en el pasado muchas de ellas sí fueron acogidas en una coyuntura muy concreta, como el Concilio Vaticano II y las primeras Asambleas Generales del Episcopado Latinoamericano (sobre todo la de Medellín y Puebla). Como respuesta a esas preguntas, los teólogos latinoamericanos construyen un método teológico que consiste en lo siguiente:

Parte de la experiencia humana, de la realidad histórica, a la que se accede no intuitivamente o a tientas y a ciegas, sino recurriendo a las ciencias sociales. Pero no se queda ahí. La realidad analizada es entendida desde la fe a través de la reflexión teológica desde el lugar social de los pobres. Los dos pasos precedentes conducen a un tercero: la praxis (Tamayo 1994, 16).

En esta metodología, la praxis es la primera palabra, lo que le otorga al comprender una importancia vital y que aparece como eje epistemológico de este comprender (se comprende cuando se experimenta). La segunda palabra es la interpretación de la realidad y el análisis de la Escritura con la finalidad de volver nuevamente a la praxis, para la aplicación de lo comprendido e interpretado al lado de los que sufren. En efecto "esto lleva a sostener que, en última instancia, el método (el camino) del discurso sobre Dios es nuestra espiritualidad" (Gutiérrez 1991, 12). 
Esta teología es un intento por partir de esas preguntas praxiológicas para encontrar en la realidad y, luego, en la Biblia, una respuesta liberadora, para después regresar a la praxis. A este proceso circular, Segundo (1970, 1975 y 1989) le llama círculo hermenéutico y él lo plantea creativamente como el método teológico, el cual está presente en los rasgos generales de las teólogas y teólogos que dieron origen a esta teología. Entre estos, se citan a Gustavo Gutiérrez, Hugo Assmann, Rubén Alves, José Míguez Bonino, Leonardo y Clódovis Boff, Jon Sobrino e Ignacio Ellacuría; por su parte, las teólogas más influyentes han sido Elsa Támez, Ivonne Guevara, Nelly Richtie, entre otras.

La circularidad va de la comprensión de la realidad que parte de la praxis liberadora a la realidad en la que se vive al texto bíblico, donde se encuentra una praxis liberadora que da luces acerca de la realidad (ayuda a comprender) para volver, entonces, al texto de la vida y así sucesivamente. En este contexto, se da la relación entre exégesis y hermenéutica como un todo. Se puede decir que la teología de la liberación, al definirse como reflexión crítica a partir de la praxis liberadora, se entiende como acto segundo en relación con el acto primero de la praxis y como palabra segunda en relación con la palabra primera de las ciencias humanas (Geffré, Galilea, Dussel, Gutiérrez, Boff, Comblin, Segundo, Vidales, Muñoz y Míguez Bonino 1974).

La teología de la liberación con la mediación de las ciencias sociales enfoca su crítica no solo hacia la sociedad, sino a la iglesia o iglesias que fundamentan sus verdades en otra hermenéutica, la de los documentos oficiales que tienden a reforzar lo institucional eclesial y proponen una lectura unívoca que funciona como una manera controlada de entender cualquier texto, donde no caben interpretaciones diferentes, ni tampoco una libertad interpretativa porque todo está dicho a priori desde lo cultural, eclesial o académico confesional.

En efecto, la teología de la liberación se caracteriza por tener rasgos críticos ante la tradición, de ahí sus cuestionamientos antiidolátricos a una teología que utiliza una hermenéutica a su conveniencia. En este sentido, según Oliveros (1980), para la teología de la liberación las ciencias sociales (en la interioridad de la praxis liberadora) son la palabra primera, en tanto que son ellas quienes aportan la capacidad de comprender la realidad desde esta experiencia liberadora: la reflexión teológica que es un acto interpretativo es solo la palabra segunda, la palabra primera es la praxis liberadora; así, como acto segundo, es la teología de la palabra primera que es la mediación de las ciencias humanas.

Para ello, Segundo (1975) propone un método teológico estructurado en varios pasos. El punto de inicio de este método es "nuestra manera de experimentar la realidad que nos lleva a su vez a la sospecha ideológica" (11). El segundo paso de este método es la aplicación de la sospecha ideológica a lo superestructural, incluyendo a la teología y, en tercer lugar, "una nueva manera de experimentar la realidad teológica que nos lleva a la sospecha exegética, es decir a la sospecha de que la interpretación bíblica corriente no tiene en cuenta datos importantes" (14). No es lo mismo leer la Biblia 
desde una perspectiva individualista y sin referencia a conocer la verdad, que leer la Biblia desde un análisis de la realidad social que ayude a conocer bien esa realidad. El buen conocimiento de esa realidad lleva a un mejor entender de la Escritura.

Esto conlleva a una nueva interpretación de los textos bíblicos y con ello rompe una larga experiencia hermenéutica de la iglesia que no se actualiza con los aportes de las ciencias sociales, pues la interpretación antes venía de las autoridades o del magisterio de la Iglesia, las cuales aclaran la visión que se tiene de la realidad. Con esto, Segundo (1975) enfatiza que existen otras maneras de interpretar la Biblia y socava el criterio de Verdad (con mayúscula) que pregona la Iglesia y que concluye con un pensamiento único irrefutable, el cual se impone a cualquier otro tipo de conocimiento de la realidad.

Por último, esto lleva a una nueva hermenéutica de interpretación de la fuente de fe (la Escritura), con nuevos elementos aportados por mediación de las ciencias sociales (Segundo, 1975). De tal manera, este autor se distancia de otras hermenéuticas que no son "nuestras" y que no toman en cuenta la realidad latinoamericana. Es necesario anotar que el concepto de sospecha del teólogo Juan Luis Segundo posee clara influencia del pensamiento de Ricoeur (1985), quien es uno de los primeros en hablar de la huella dejada en la hermenéutica por los tres grandes artífices de la sospecha: Friedrich Nietzsche (1844-1900), Karl Marx (1818-1883) y Sigmund Freud (1856-1939).

Para Segundo (1970), la sospecha ideológica es imprescindible porque no es posible hacer teología si se vive la vida cristiana de manera ingenua, o sea, sin creer y por lo menos en este primer nivel, debe expresarse en una actitud de búsqueda. Por eso, "podrá existir una teología que trate de la liberación, pero su ingenuidad metodológica le será, tarde o temprano, fatal" (12). Asimismo, este autor considera la necesidad de "la aplicación de la sospecha ideológica a toda la superestructura ideológica en general y en particular a la teología" (14).

En este aspecto, Segundo (1970) promueve una visión desde el materialismo dialéctico de la superestructura ideológica. Desde esa perspectiva, se levanta la sospecha ideológica a todo el aparato ideológico que incluye lo religioso y lo teológico. La crítica ideológica de este autor es muy afín con el pensamiento crítico de Jürgen Habermas, aunque ambos pensadores poseen diferencias sustanciales. Para Habermas (2008), los conflictos de los diversos sectores sociales se deben precisamente a las ideologías. Si no se logra una interpretación adecuada de la realidad es porque, en muchas ocasiones, por la presión que ejercen estas y que impiden explorar los verdaderos intereses de esos grupos.

Efectivamente, para Habermas (2008): "La crítica ideológica descifraba en las ideas utilizadas de ese modo un fragmento de razón existente oculto a sí mismo, y leía esas ideas como una directriz que podía poner por obra los movimientos sociales" (135). En este autor, la crítica ideológica permite discernir las verdaderas intenciones que se mueven y buscar un consenso me- 
diante el diálogo. En esto último, posiblemente se encuentra una pequeña diferencia entre Juan Luis Segundo y Jürgen Habermas, debido a que el primero de estos autores pareciera realizar la crítica ideológica para falsear el edificio ideológico de la ortodoxia.

La precomprensión como sospecha ideológica implica, a su vez, la necesidad de una teoría que auxilie la labor comprensiva, de ahí la necesidad de la teología en relación con las ciencias sociales. Si no se comprende la exigencia de colocar a la teología al lado de las ciencias sociales, no es posible "interpretar la Escritura dirigida a nosotros, hoy y aquí. Sin esta conexión no existe, a la larga, teología de la liberación" (Segundo 1975, 12). Respecto a tal alianza entre teología y ciencias sociales, este autor enfatiza que "La diferencia fundamental entre un teólogo académico y un teólogo de la liberación está en que este último se ve obligado a cada paso a poner juntas las disciplinas que le abren el pasado y las disciplinas que le explican el presente" (13).

Lo expresado se refiere estrictamente al método de la teología que combina, por un lado, las disciplinas que explican el presente y que tienden a interpretar la historia y, en segundo lugar, la tarea interpretativa propiamente tal en referencia a la Escritura. Para Segundo (1975), los resultados analíticos para comprender la realidad (con la asistencia de las ciencias sociales), se deben encaminar a esta búsqueda fundada en la sospecha exegética, de la cual surge la precomprensión del texto bíblico como un texto liberador de las opresiones sociales e individuales para, finalmente, volver a la praxis liberadora y proponer una nueva lectura bíblica que dé respuesta a las interrogantes de las personas explotadas latinoamericanas.

En el desarrollo del modelo del método teológico latinoamericano, y muy concretamente en el método propuesto por Juan Luis Segundo, denominado círculo hermenéutico, es donde se puede notar de manera nítida la relación entre la teología y las ciencias sociales. Además, Segundo (1975) identifica el método teológico con un proceso de circularidad interpretativa que es "el continuo cambio de nuestra interpretación de la Biblia en función de los continuos cambios de la realidad presente, tanto individual como social" (56). La Biblia genera una unidad implícita entre el texto que expresa la experiencia de Dios, en un pueblo, el exégeta que intenta comprenderlo y la Iglesia (entendida como pueblo de Dios) en su dimensión pastoral, llamado a retroalimentar la vida cotidiana con los insumos logrados en la comprensión del texto. De esta manera, comprensión e interpretación se extienden en un todo unitario con la aplicación del texto.

Para Segundo (1975), la sospecha ideológica que es parte de su hermenéutica le lleva a la sospecha exegética y, al confirmarla, permite una reflexión teológica que verifica la sospecha como verdad para aplicarla nuevamente en la praxis liberadora en la realidad, en un constante ir y venir de la praxis al texto y viceversa, sin agotar la reserva de sentido ni de la realidad ni del texto bíblico. Es un "continuo cambio de la interpretación de la Biblia en función de los continuos cambios de nuestra realidad presente, tanto individual como social" (12). 
Más recientemente, además de la preocupación por los seres humanos oprimidos, esta teología asume un fuerte compromiso por nuevos sujetos, uno de ellos es el planeta en crisis. En este sentido, Boff (1996) señala la urgencia de crear conciencia y trabajar a favor del planeta. Zaldívar (2008), por su parte, menciona otra característica de la teología de la liberación, la cual es el sentido emancipador y reivindicativo (compasivo) que le caracteriza, en tanto promueve la vida y la lucha de los humillados con el fin de superar esas condiciones históricas sociales en las que viven millones de personas en condiciones infrahumanas.

Igualmente, Gutiérrez (1977) externa otra característica de la teología de la liberación, la cual consiste en negar los procesos de muerte para revertirlos como tarea para sembrar y desarrollar la vida plena que habla del Evangelio. Es un accionar desde el reverso de la historia, porque es allí donde están las víctimas de esta opresión. Desde estos sectores silenciados y sin voz es donde surge el proceso liberador. Asimismo, para Assmann (1976), la teología de la liberación logra un cuestionamiento crítico desde la praxis iluminada por la fe que se alimenta, a su vez, de la relectura bíblica. A partir de esa perspectiva, asume una ideología desde el oprimido que le permite desenmascarar las instancias de manipulación y de legitimación del discurso oficial y proponer una sociedad alternativa. En efecto, la mediación hermenéutica es, para Boff (1980), "la relación necesaria de una Teología de lo Político con las fuentes cristianas, que confieren a esta teología su identidad propia. De este modo, las escrituras cristianas son un recurso teórico obligatorio y constitutivo de todo proceso teológico" (251).

Ir a las fuentes de la teología, en especial a la Escritura para apreciar nítidamente como el Dios cristiano alimenta, recrea la vida y la protege en toda su plenitud de una manera decidida y constante, le permite respetar toda forma de vida y buscar la justicia. En estos contextos, la teología y las ciencias sociales deben unir sus esfuerzos para lograr una nueva hermenéutica.

\section{Crítica del método desde la perspectiva de la hermenéutica filosófica (Hans-Georg Gadamer) y sus implicaciones a la teología}

En el contexto actual, es necesario repensar algunas ideologías y paradigmas con respecto al campo del método. No se puede iniciar un nuevo camino si no se conoce y se hace introspección de lo pasado, pues ha surgido un nuevo paradigma en este campo metodológico, se trata de encontrar una racionalidad orientada a la consecución de comprensiones que surgen de lo consensual. Efectivamente, para Villarroel (2002), la razón se debe centrar en la fuerza de la comunicación, la cual ha de buscar el entendimiento entre las personas y dejar de lado cualquier aspiración de controlar o dominar con la intención de imponer ciertos intereses. Esta racionalidad así comprendida se adapta de manera más apropiada al mundo de la vida y, por supuesto, al espacio experiencial de los seres humanos que interactúan socialmente. 
En este sentido, Gadamer (2004) propone debatir acerca de la crítica del método, donde se incluya el positivismo y otros métodos de las ciencias sociales. Para este autor, es imprescindible partir de la precompresión de la persona, pues nadie escapa a ello; para él, toda precompresión debe estar abierta a otras precompresiones, puesto que no se puede comprender un texto si no se aprende su sentido profundo. Si una persona se acerca con un paquete preconcebido alineado hacia una determinada interpretación, esta es monodialogal, ya que la verdad no surge del diálogo, sino del acto unilateral que se concreta al final del consenso fáctico.

Esto significa que la precompresión pasa por un método previamente escogido que, a su vez, direcciona de hecho los resultados a los cuales se llegará. Si bien es posible un cierto consenso, este se establece fundamentado en posiciones ya asumidas, elaboradas previas a cualquier diálogo, que se concretan con base en el mejor argumento previamente consensuado (no hay verdadera confrontación de ideas). Gadamer (2004) cuestiona este acercamiento ideológico cuando afirma que la búsqueda del consenso "consiste en no partir de ese consenso contra-fáctico, sino en posibilitarlo y convencer mediante una crítica concreta" (261).

De este modo, Gadamer (2004) expresa que el consenso surge de la exposición de los prejuicios como válidos. El consenso surge cuando se valoran estos prejuicios y se logra concertar sobre la validez de uno de los prejuicios orientadores. Es un ejercicio de comprenderse individual y socialmente en el contexto, donde el diálogo y la apertura a lo distinto es imprescindible. Precisamente, en eso consiste el diálogo y es por medio de la confrontación que se va dilucidando la validez en alguno de los prejuicios sometidos al debate, porque "la influencia de un prejuicio orientador ayuda a enmendar los prejuicios anteriores vigentes. Aquí no se aplica a los textos lo que está en ellos, porque se pone al descubierto el prejuicio del otro" (253). Esta evidencia solo se alcanza porque se mira lo real que hay en ellos mediante una visión diferente.

Este enfoque que cuestiona dicho carácter del método, cualquiera que sea, obstruye la búsqueda de verdades y obnubila posibles comprensiones no previstas en un determinado enfoque ideológico. En tal contexto, solo son posibles dos opciones: la imposición de uno de los enfoques de manera forzada o el entrabamiento en la búsqueda del consenso por la inflexibilidad de las posturas ideológicas. Lo primero lleva a la imposición unilateral; lo segundo, a la anarquía o a la ingobernabilidad. Por ello, Gadamer (2004) propone la comprensión de lo distinto mediante la aceptación de los prejuicios, como escenario previo a la búsqueda de la verdad. Si se regresa al ejemplo de la sospecha ideológica en Juan Luis Segundo (viéndola como prejuicio) es, sin duda, crítica ideológica hacia afuera, cuestionando toda ideología que subyace en el pensamiento teológico, pero tiene ciertas limitaciones autoevaluativas, ad intra.

Esta es una dificultad que se debe solventar en los discursos ideológicos. Por eso es importante retomar de Gadamer (2004) su cuestionamiento de todo método en la tarea interpretativa y la valorar un nuevo acercamiento al que- 
hacer teológico por la vía de la hermenéutica filosófica. "La hermenéutica filosófica puede hacerse práctica: vuelve sospechosa cualquier ideología poniendo en evidencia los prejuicios" (252). Para este autor, no existen la objetividad ni posiciones objetivas, sino que cada uno parte de sus prejuicios. En este sentido, toda persona puede lograr verdades relativas y no se pueden anular otros posibles argumentos, los únicos argumentos no valederos son aquellos mediados por dogmas, absolutos o posiciones únicas, incapaces de someterse a la duda, a la crítica, al imperativo de que nada es verdad, ni absoluto.

Las ideas de Hans-Georg Gadamer están dirigidas a obstruir los métodos que no permiten una dinámica dialógica. Todo método impide el diálogo, en tanto que lleva en sí la verdad escondida que ha de imponerse y que se acepta o se rechaza, sin ninguna otra posibilidad. Perdiéndose, de esta manera, la oportunidad de entablar un verdadero diálogo donde las personas puedan participar sin exclusiones.

A partir de este pensamiento, nace una preocupación por el enfoque que expone Hans-Georg Gadamer, debido a su carácter inclusivo, o con lo que respecta al método, el enfoque mantiene un carácter emancipatorio que se relaciona con la teología latinoamericana. Gadamer (2004) cree que la hermenéutica filosófica incide en un carácter verdaderamente emancipatorio y más bien pone en tela de juicio el carácter emancipador preestablecido porque proviene de absolutos externos a la conciencia, que se enmarcan en filosofías del deber ser, donde no media un proceso educativo, sino ideológico, proponiendo un acercamiento fenomenológico-ontológico que lleve al ser a una verdadera comprensión y, al mismo tiempo, a una emancipación desde la conciencia.

Otro cuestionamiento de Gadamer (2004) a lo metodológico es que la dimensión histórica no se plasma desde una perspectiva ideológica muy ligada a lo teórico, sino que se manifiesta en la cotidianidad y que es importante percibirla desde una perspectiva fenomenológica. Si bien, para Juan Luis Segundo, la comprensión de lo histórico viene desde la praxis, se experimenta la realidad desde una perspectiva histórica, se interpretan los textos bíblicos en una dimensión histórica y se apunta hacia una perspectiva liberadora en la historia. El acercamiento hacia lo histórico proviene de la sospecha ideológica, precisamente de su dimensión histórica y sirve para discernir el papel legitimador de la teología como superestructura ideológica en una determinada época histórica. En Hans-Georg Gadamer, esta dimensión histórica resulta ser distinta a la dimensión histórica de la vida cotidiana, donde no se parte de marcos ideológicos preconcebidos.

Para Gadamer (2004), el ser humano es un ser histórico concreto en el mundo de la vida fáctica, es decir, preteórica, cuyo carácter principal es el comprender. Este autor considera que, desde esta perspectiva ontológica, la transformación de la conciencia se realiza dentro de su propia tradición y cultura, esto hace más efectivo el cambio emancipatorio. El problema del método utilizado desde las ciencias sociales es que la transformación de la conciencia se hace a partir de marcos ideológicos preestablecidos que no toman 
en cuenta ni la cultura, ni el ser en su cotidianidad. En este enfoque está el hilo conductor de tal pensamiento de Hans-Georg Gadamer, que es su escepticismo contra todo dogmatismo. Asimismo, este pensador cuestiona la dimensión histórica que busca criterios absolutos para valorar lo cotidiano-histórico, separándose así del sentido rescatable desde la cotidianidad que aclara algo noble procedente de la complejidad de lo fáctico. Además, este autor expresa que no es posible transformar la historia desde presupuestos teóricos que se alejan del mundo de lo fáctico, debido a que:

La experiencia de la historia no es la experiencia del sentido, del plan y de la razón, y sólo desde la visión perennizante de la filosofía del saber absoluto se podría pretender concebir la razón en la historia. De este modo la experiencia de la historia reconduce en realidad la tarea hermenéutica a su verdadero lugar. Esa tarea consiste en descifrar constantemente los fragmentos de sentido de la historia que se limitan a la oscura contingencia de lo fáctico y se quiebran en ella, y sobre todo en la penumbra que envuelve al futuro para toda la conciencia presente (255).

En referencia con lo expuesto, el pensamiento de Hans-Georg Gadamer se interpreta desde la tradición, pero no para validar el statu quo, sino para modificarlo, para cambiarlo de manera paulatina, no abrupta o revolucionaria, sino de las raíces profundas del ser. Para muchos, este enfoque tiene mucho de conservador y defensor del statu quo, en ello se advierte el peligro de un análisis de la tradición que tienda a consolidar lo establecido desde una perspectiva conservadora dirigida a dejar las cosas como están. No obstante, el autor refuta esta crítica, pues no es posible un verdadero cambio en la conciencia si no se parte de la vivencia cotidiana y no de un modelo transformador preestablecido, se construye lo nuevo a partir de lo viejo; de alguna manera, es un reciclaje de la tradición, donde se toman aspectos de lo antiguo y se articula lo original que emerge de esta dialéctica en una nueva síntesis.

Por su parte, para Segundo (1989), optar por la tradición escritural es "optar por los mismos valores y por las mismas señales históricas referidas a tales valores" (383). Este autor extiende su explicación de la tradición cuando manifiesta que "Moisés no enseña en el Éxodo una respuesta hecha de una vez para siempre, sino que pone en movimiento un proceso de aprender a aprender, descubriendo señales de la presencia reveladora de Dios en la historia" (383). Por ende, para este teólogo, dogma es la búsqueda sistematizada por medio de una tradición "de una verdad que dé un sentido más hondo y rico a 
la existencia humana. $Y$ este sistema no es otra cosa que una tradición en la que se cree reconocer una pedagogía divina" (223).

Desde la perspectiva del párrafo anterior, el análisis hermenéutico propuesto requiere de las ciencias sociales para comprender la realidad y en ese propósito, el pensamiento teológico latinoamericano asume un análisis coincidente con el propósito emancipador que pretende la teología. Asimismo, Segundo (1989) observa de las partes a lo general y viceversa como criterio de revelación en el proceso interpretativo del círculo hermenéutico. El círculo hermenéutico es un constante ir y venir de la realidad a la interpretación bíblica en función de los continuos cambios de la realidad presente, tanto individual como social. Para ello, este teólogo expresa que "Hermenéutica significa interpretación. Y el carácter circular de dicha interpretación va en que cada nueva realidad obliga a interpretar de nuevo la revelación de Dios, a cambiar con ella la realidad, a volverla a interpretar y así sucesivamente" (12).

Ese volver a la realidad no es una lectura ingenua de la realidad, sino una mediación socioanalítica previa de la lectura bíblica. No se puede comprender el texto bíblico (de eso trata toda teología cristiana), sino que se hace una lectura de la realidad. Por tanto, la hermenéutica de Juan Luis Segundo intenta establecer una relación adecuada entre teología y ciencias sociales, porque esta relación presupone una teoría correspondiente a una teología que asuma críticamente la lectura de la realidad y que se sale de una interpretación ingenua de esa realidad.

Para Yuste (2011), no sería posible tal lectura con una sociología acrítica de la realidad, por el contrario, esta perspectiva crítica de la teología tiende a evitar las ingenuidades ideológicas de la teología ortodoxa, desenmascara sus intereses ocultos y permite una lectura de la historia. Asimismo, los teólogos de la liberación no reivindican una mayor objetividad o una menor carga ideológica para los análisis que asumen o para los proyectos a los que se adhieren. "Lo que afirman, a la luz de la fe, es que todos los análisis y todos los proyectos tienen una relación histórica con la salvación cristiana y que no todos los análisis, ni todos los proyectos, tienen igual valor en relación con esa salvación" (121).

Por su parte, Gadamer (2004) no permite la mediación de otras ciencias dentro del proceso hermenéutico propiamente. Para este autor, la comprensión no puede encasillarse en un método, ni el método científico, ni el método de las ciencias sociales. La hermenéutica es una vía, un camino para ayudar a comprender, no compatible con la ciencia.

Ahora bien, Hans-Georg Gadamer es un referente clave en el pensamiento de Juan Luis Segundo, principalmente, se puede constatar esta influencia en el concepto de círculo hermenéutico, donde expone los cuatro principios que explicitan su teoría hermenéutica. Si bien este concepto es utilizado primero, a nivel teórico, por Martin Heidegger, por Paul Ricoeur y Hans-Georg Gadamer en el campo filosófico y por Rudolf Bultmann en el ámbito teológico, es por medio de Juan Luis Segundo que se convierte a modo de ejercicio práctico. Por eso, no es posible la comprensión de este concepto en Juan Luis Se- 
gundo sin estas influencias, en especial la de Hans-Georg Gadamer. Además, se destaca que la influencia de Hans-Georg Gadamer en Juan Luis Segundo se da no solo en el círculo hermenéutico, sino también en la sospecha que está relacionada al concepto de la aceptación de los prejuicios.

Estos los hace parte del círculo hermenéutico estos dos últimos conceptos y los denomina como la sospecha ideológica. La posibilidad de la sospecha tiene dos interpretaciones probables: la primera, consiste en que no se puede leer un texto sin tomar en cuenta los prejuicios implícitos, "que son los que permite que algo encontrado en el texto adquiera un sentido (significativo) para nosotros" (Mejía 2016, 198), y la segunda radica en la posibilidad de aceptar los prejuicios como parte de criterios que emite el texto con el fin de buscar consensos. Es necesario recordar que el primer criterio del círculo hermenéutico de Juan Luis Segundo reside en experimentar la realidad que lleva a la sospecha ideológica. Este criterio de desideologizar el texto de viejas ideologías que ya han perdido su eficacia o que se manipulan para reforzar doctrinas deshumanizadoras y poco liberadoras es clave en el método de este teólogo. Asimismo, en el tercer paso del círculo hermenéutico se encuentra la clave liberadora, ligada a la nueva forma de experimentar la realidad, la cual produce otra sospecha: la sospecha exegética que motiva a realizar una nueva lectura liberadora de la Escritura.

En efecto, los resultados de la hermenéutica sí pueden ser aplicados en otras ciencias como el enfoque epistemológico (ruptura epistemológica) y el enfoque ontológico (ruptura con lo fáctico o los absolutos). La hermenéutica es el sentido que cada persona le quiere aplicar. Las otras ciencias, aunque no lo quieran, requieren de interpretaciones, las cuales deben corresponder a lugar, tiempo, espacios, necesidades, entre otras, que buscan cumplir con cuanto se quiere.

\section{Conclusión: apuntes finales con respecto a la teología y las ciencias sociales}

El aporte que puede hacer Gadamer (2004) a la teología y a las ciencias sociales es fundamental, debido a que abre la posibilidad de construir una interpretación incluyente que fomente el diálogo y la búsqueda de consensos. Este autor considera que todo texto es comprendido e interpretado desde la perspectiva del lector, quien, a su vez, no tiene un proyecto propio, sino colectivo, basado en la tradición. Porque todo lector inicia la interpretación de un texto no de cero, sino de una conciencia forjada cultural e históricamente que va variando y reformulando de acuerdo con esta precomprensión, produciéndose así un proceso que se puede prolongar indefinidamente. Este aporte lleva a la teología a surgir desde la praxis histórica de comunidades y no solo del teólogo como individuo ilustrado.

Para Gadamer (2004), el factor comunidad es primario porque "la anticipación de sentido que guía nuestra comprensión de un texto no es un acto de la subjetividad, sino que se determina desde la comunidad que nos une con la 
tradición" (363). Cuando se interpreta un texto, se produce una fusión de horizontes donde se articula la historia del texto con el propio trasfondo cultural e histórico de las personas. Se sigue con ello el proceso interpretativo que se hace todos los días, incluso cuando no se es consciente de que esto ocurre. Por lo tanto, no se puede afirmar que en un texto solo hay una interpretación definitiva, debido a que siempre está abierto a nuevas interpretaciones. Lo importante es tener mente abierta a nuevas comprensiones para no caer en el dogma interpretativo, en el cual solo existe una interpretación.

Hans-Georg Gadamer cuestiona enfoques que pretenden equiparar el método de las ciencias humanas al método científico, como aquel método que pretende comprender el texto a partir de la intención original del autor que lo escribe. Este enfoque significa poner un límite a toda comprensión totalitaria y, a la vez, un salirse del conceptualismo individualista abstracto. Lo importante es saber que en el texto hay una reserva de sentido en la interpretación de la realidad que deja inconclusa y no acabada la interpretación del texto, por el contario, la deja abierta a nuevos caminos, tal vez este sea el gran miedo.

Por su parte, para Segundo (1989), lo emancipatorio que él denomina como liberación se orienta por una transformación de las causas económicas y culturales mediante el cambio de la conciencia religiosa, mediada por las ciencias sociales. La teología orienta y acompaña ese camino crítica y autocríticamente. Este teólogo escribe su obra en el marco de una coyuntura marcada por la confrontación entre capitalismo y socialismo; la coyuntura actual podría ser desfavorable para ese camino.

En efecto, el aporte que realiza Hans-Georg Gadamer puede llevar a pensar que abriría nuevas perspectivas de desarrollo a la teología de la liberación, en tanto es necesario que se distancie del discurso ideológico que explícitamente cuestiona otros discursos no compatibles y abrir el espacio a la inclusión de los prejuicios, con apertura al diálogo y a la búsqueda de consensos sobre temas claves para la convivencia humana.

Además, para Gadamer (2004), poner sobre la mesa los prejuicios permite una búsqueda de verdades, donde todos los puntos de vista se asumen con seriedad y donde es posible ponerse de acuerdo para comprender mejor los problemas de la humanidad. De este modo, todos los sectores y todas las opiniones se toman en cuenta, no hay exclusiones. ¿Es un modelo inclusivo o ingenuo o iluso? ¿No crea una ruptura este pensamiento gadameriano con el monopolio de las ciencias naturales y de las ciencias sociales como las únicas posibilidades de conocer la verdad?

Es interesante que, dentro de la misma teología de la liberación, se hayan levantado voces que pretenden buscar otro camino. Por ejemplo, Boff (1980) reivindica la importancia del sentido común y de la sabiduría popular que pueden comprender el mundo de la opresión con mayor eficiencia y desde otras perspectivas, diferentes al conocimiento erudito y por medio de una crítica que supera el saber de los expertos. Por su parte, para Yuste (2011), no se trata de reivindicar un intuicionismo, sino de afirmar que la idea de lo so- 
cialmente vivido es lo que da carne y sangre a un conocimiento elevado de un concepto en lo socialmente conocido.

Desde una perspectiva gadameriana, es tal la imposibilidad de comprender lo otro que es necesario suspender el juicio (la epojé) porque hacer un juicio se vuelve imposible dado que no se tiene toda la información de lo otro como para llegar a alguna conclusión. Por ello, la interpretación de lo otro se efectúa desde la subjetividad de cada individuo, intentando comprenderlo adentrándose en la subjetividad de lo otro. La comprensión se logra en la fusión de horizontes de ambas perspectivas, conclusión que no es más que algo transitorio, la cual queda abierta a nuevas reinterpretaciones y así hasta el infinito.

Una conclusión sumamente importante es reafirmar una espiritualidad desde el sufrimiento, muy propio de la teología de la liberación, cuya pretensión ha sido siempre remarcar el carácter liberador de la fe cristiana y aprender a crecer en medio de la lucha (resiliencia). En el momento actual, el tema de la espiritualidad es fundamental. La teología de la liberación podría ser un aporte significativo en el desarrollo de las mismas teologías latinoamericanas, en las cuales este énfasis siempre estuvo presente en una espiritualidad desde el sufrimiento de los sectores pobres y en desventaja social, aspecto que marca una nueva dimensión a veces olvidada por algunos teólogos de la liberación que se inclinaron más por cierta tendencia hacia la ideologización de la fe.

La búsqueda de una espiritualidad de la teología de la liberación se destacó por el aporte de Gustavo Gutiérrez en su libro Beber en su propio pozo, que es una invitación a reflexionar sobre una nueva espiritualidad surgida desde los sectores pobres y en desventaja social en Latinoamérica. Algunas otras obras en esa misma línea, del mismo Gustavo Gutiérrez, son: El Dios de la vida y Hablar de Dios desde el sufrimiento del inocente: una reflexión sobre el libro de Job. También, el libro de Pedro Casaldáliga, Espiritualidad de la liberación, y el de José María Castillo Sánchez, El seguimiento de Jesús, abordan esta nueva espiritualidad.

Otra conclusión importante es la concepción de ideología en la teología de la liberación. Un común denominador del uso de este concepto es su alejamiento de todo dogmatismo y el carácter pragmático que, en muchas ocasiones, los teólogos de la liberación le dan a este concepto. Por ejemplo, la ideología en Juan Luis Segundo si bien parte de un enfoque dialéctico, propio de la Escuela de la Frankfurt (el materialismo histórico), lo matiza con aspectos propiamente teológicos. Lo superestructural refiere al ámbito de la educación, la cultura y la religión, pero se aclara que en este autor el uso de la ideología no es absoluta, sino flexible. Para Juan Luis Segundo, lo superestructural refiere al concepto de fe antropológica que significa la posibilidad de amar incondicionalmente, tanto de los creyentes como de los no creyentes. Este autor habla de construir una ideología del amor, a la cual llama fe antropológica, la cual es la fe en los mismos valores de Dios. Si tenemos fe en el amor, se puede tener una fe como una ideología del amor. Por eso, Juan Luis Segundo tenía un gran respeto por las personas que no creen en Dios. 
En el caso de la fe cristiana, la diferencia no es la fe en el amor como un valor, sino en el amor encarnado en Cristo. Para Juan Luis Segundo, la vida de fe se expresa en una práctica que se fundamenta en una ideología donde se manifiesta el amor. Ante las demandas de la realidad, este autor propone una pedagogía de la fe que consiste en responder a las demandas de la realidad desde los valores de Dios, manifiestos en su Hijo Jesucristo (Iglesias 2016).

También, una conclusión importante que aporta Juan Luis Segundo es la necesidad de incorporar otros sujetos en el quehacer teológico. Sin duda hay un crecimiento muy grande de jóvenes que tienen interés por conocer más de la teología, pero una teología que incorpore los nuevos paradigmas de la posmodernidad. El afán de este autor es dialogar con el ser humano moderno, sea creyente o no lo sea, para mostrarle la libertad radical que se encuentra en Jesús. Por eso, no es casualidad que diversos investigadores creyentes y no creyentes sean admiradores de este autor, incluso han escrito diferentes obras partiendo de la metodología planteada por Juan Luis Segundo, en las cuales se pretende emular su metodología en múltiples temáticas.

Ciertamente, y como conclusión final, se encuentra en este artículo un vacío al no incorporar suficiente de lo expresado por Clódovis Boff en su obra Teología de lo político así como otros teólogos de la teología de la liberación; aunque, por supuesto, se reconoce que es mucho lo que se debe citar de estos autores. Tal vez, la ausencia de algunos autores de la teología de la liberación y del mismo Clódovis Boff se deba a que no toma aspectos particulares de Juan Luis Segundo que sí se querían dar a conocer en este estudio, en especial la preocupación por una síntesis entre el análisis social y su hermenéutica.

\section{Bibliografía}

Assmann, Hugo. 1976. Teología desde la praxis de la liberación: ensayo teológico desde la América dependiente. Salamanca: Sígueme.

Ayllón, José, Marcial Izquierdo y Carlos Díaz. 2018. Historia de la filosofía. Barcelona: Ariel.

Benzo, Miguel. 1978. Hombre profano, hombre sagrado: tratado de antropología teológica. Madrid: Cristiandad.

Boff, Clódovis. 1980. Teología de lo político: sus mediaciones. Madrid: Sígueme.

Boff, Leonardo. 1996. Ecología: grito de la tierra, grito de los pobres. Madrid: Trotta.

Espeja, Jesús. 1997. Para comprender mejor la fe: una introducción a la teología. Salamanca: San Esteban.

Floristán, Casiano, y Juan José Tamayo. 1985. El Vaticano II, veinte años después. Madrid: Cristiandad. 
Gaboriau, Florent. 1970. El giro antropológico de la teología de hoy. Barcelona: Herder.

Gadamer, Hans-Georg. 2004. Verdad y Método II. Salamanca: Sígueme.

Geffré, Claude, Segundo Galilea, Enrique Dussel, Gustavo Gutiérrez, Leonado Boff, José Comblin, Juan Luis Segundo, Raúl Vidales, Ronaldo Muñoz, y José Míguez Bonino. 1974. Praxis de liberación y fe cristiana. El testimonio de los teólogos latinoamericanos. Concilium 96: 301-447.

Gutiérrez, Gustavo. 1977. Teología desde el reverso de la historia. Lima: CEP.

Gutiérrez, Gustavo. 1991. Teología de la liberación: perspectivas. Lima: CEP.

Habermas, Jürgen. 2005. Ciencia y técnica como ideología. Madrid: Tecnos.

Habermas, Jürgen. 2008. El discurso filosófico de la modernidad. Madrid: Katz.

Iglesias, Nicolás. 2016. Juan Luis Segundo, teólogo uruguayo adelantado a su tiempo. Recuperado de http://dioseslocos.org/juan-luis-segundoteologo-uruguayo-adelantado-a-su-tiempo

Keller, Werner. 1957. Y la Biblia tenía razón. La verdad histórica comprobada por las investigaciones arqueológicas. Barcelona: Omega.

Ladaria, Luis. 2000. El Dios vivo y verdadero: el misterio de la Trinidad. Salamanca: Secretariado Trinitario.

Marion, Jean-Luc. 2007. ¿Es el argumento ontológico realmente ontológico? El argumento sobre la existencia de Dios según San Anselmo y su interpretación metafísica en Kant. Tópicos 32: 179-205.

Mancilla, Sandro. 2006. Interpretación y fe: una breve presentación de la hermenéutica teológica de Paul Ricouer. Teología y Vida 47: 531-539.

Mejía, Álvaro. 2016. Manual de contra teología y teología corregida. Bogotá: Universidad de Santo Tomás.

Míguez Bonino, José. 1977. La fe en busca de eficacia. Una interpretación de la reflexión teológica latinoamericana de liberación. Salamanca: Sígueme.

Oliveros, Roberto. 1980. Liberación y teología: génesis y crecimiento de una reflexión (1966-1976). Lima: Centro de Estudios y Publicaciones.

Pié i Ninot, Salvador. 2005. La teología fundamental: dar razón de la esperanza (1 Pe 3,15). Salamanca: Secretariado Trinitario.

Rahner, Karl. 2007. Escritos de Teología. Tomo IV. Escritos recientes. Madrid: Cristiandad.

Ricoeur, Paul. 1985. Freud: una interpretación de la cultura. México: Siglo XXI. 
Segreda, Luis. 2011. Fe cristiana y derechos humanos. San José: SEBILA.

Segundo, Juan Luis. 1970. De la sociedad a la teología. Buenos Aires: Lohlé.

Segundo, Juan Luis. 1975. Liberación de la teología. Buenos Aires: Lolhé.

Segundo, Juan Luis. 1989. El dogma que libera: fe, revelación y magisterio dogmático. Santander: Sal Terrae.

Taborda, Francisco. 1981. Fe crista e praxis histórica. REB 41(162): 250-278.

Tamayo, Juan José. 1994. Presente y futuro de la teología de la liberación. Madrid: San Pablo.

Velasco, Rufino. 1998. Teología del siglo XX. Bilbao: Sal Terrae.

Vigil, José María. 2005. Teología del pluralismo religioso: curso sistemático de teología popular. Córdoba: Los Almendros.

Villarroel, Rafael. 2002. Programa educación en valores: Perspectivas éticas. Cyber Humanitates, 21. Acceso el 20 de febrero de 2019. https://web.uchile.cl/vignette/cyberhumanitatis/CDA/vida_sub_simple3/0 ,1250,PRID\%253D1076\%2526SCID\%253D1079\%2526ISID $\% 253 \mathrm{D} 5,00 . \mathrm{html}$

Yuste, Rafael. 2011. Pensamiento cristiano y política. Acceso el 15 de febrero de 2019. https://dokumen.tips/documents/yuste-rafael-pensamientocristiano-y-politica.html

Zaldívar, Raúl. 2008. Teologia sistemática: Desde una perspectiva Latinoamericana. Barcelona: Clie. 